Research Paper:

\title{
The Relationship of Basic and Instrumental Activities of Daily Living With the Risk of Developing Pressure Ulcer
}

\author{
Sahar Mohammadi' (D), Forough Rafii ${ }^{2 *}$ (D), Tahmine Salehi' ${ }^{1}$ (D) Hamid Haghani ${ }^{3}$ (D) \\ 1. Department of Nursing, School of Nursing and Midwifery, Iran University of Medical Sciences, Tehran, Iran. \\ 2. Nursing Care Research Center, School of Nursing and Midwifery, Iran University of Medical Sciences, Tehran, Iran. \\ 3. Department of Biostatics, School of Health, Iran University of Medical Sciences, Tehran, Iran.
}

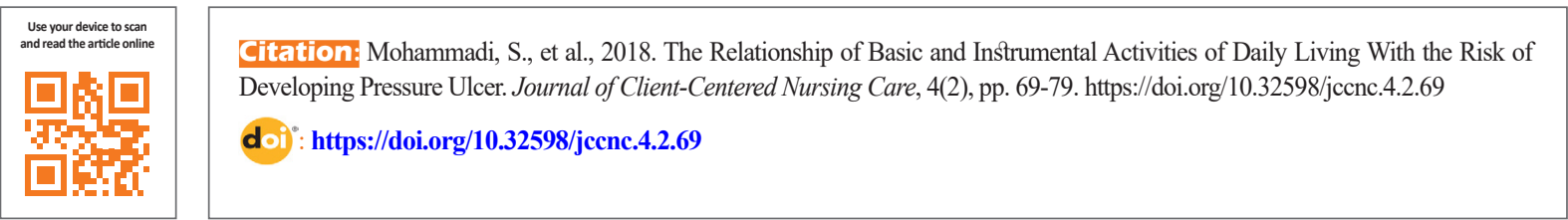

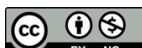

Funding: See Page 69

Article info:

Received: 14 Dec 2017

Accepted: 26 Mar 2018

Published: 01 May 2018

Keywords:

Basic activities of daily living, Instrumental activities of daily living, Pressure ulcer

\begin{abstract}
A B S T R A C T
Background: The basic and instrumental activities of daily living are prerequisites for living with a good quality of life. On the contrary, lack of movement and physical inactivity are considered as the main cause of pressure injuries. Accordingly, this study aimed to determine the relationship between the basic and instrumental activities of daily living with the risk of pressure ulcers in patients referred to educational health care centers affiliated to Iran University of Medical Sciences in 2017.
\end{abstract}

Methods: This descriptive, cross-sectional study was conducted on 200 patients referred to internal and surgical clinics of hospitals affiliated to Iran University of Medical Sciences. The sample was recruited by cluster sampling method. The study questionnaires included four sections: a demographic from, Katz Scale of Basic Activities of Daily Living (BADL), Lawton Scale of Instrumental Activities of Daily Living (IADL), and Braden pressure ulcer risk assessment scale. Data was analyzed by Independent t test, ANOVA, Pearson correlation coefficient, and Spearman correlation test using SPSS-PC V. 24.

Results: With higher dependence in performing BADL and IADL, the risk of pressure ulcer development increased $(\mathrm{P}<0.001)$. The relationship was even higher with regard to IADL. Dependence in all subscales of BADL and IADL was directly related to the risk of developing pressure ulcer $(\mathrm{P}<0.001)$.

Conclusion: The degree of dependence in BADL and IADL can be considered as one of the predictors of pressure ulcer development. It is necessary to plan appropriately to increase the independency of patients in performing such activities.

\footnotetext{
* Corresponding Author:

Forough Rafii, PhD.

Address: Nursing Care Research Center, School of Nursing and Midwifery, Iran University of Medical Sciences, Tehran, Iran.

Tel: +98 (912) 2979914

E-mail: rafiee.f@iums.ac.ir
} 


\section{Highlights}

- Higher dependence in performing basic and instrumental activities of daily living increases the risk of pressure ulcer.

- Basic activities of daily living is more important than instrumental activities in the development of pressure ulcer.

- All subscales of basic and instrumental activities of daily living are associated with the development of pressure ulcer.

- The degree of dependence in basic and instrumental activities of daily living can be one of the predictors of pressure ulcer development.

\section{Plain Language Summary}

Daily living activities like bathing, dressing, and instrumental daily activities like shopping or housekeeping decrease the risk of bed sore. It is particularly important in patients aged above 45 years with chronic diseases. The degree of dependence in daily activities can be one of the predictors of bed sore development. Therefore, in the field of education, it is necessary to hold training classes and methods for nursing staff in order that they teach empowerment techniques to their patients. Also training programs for patients, public community, especially older people should be held with respect to strategies for increasing their independence. Family members of at-risk patients should plan appropriately to increase the independency of the patients in performing such activities. Most importantly, patients who are at risk must try to manage their activities independently as far as they can.

\section{Background}

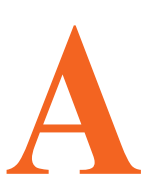

ccording to The National Pressure Ulcer Advisory Panel (NPUAP), Pressure Ulcer (PU) is defined as a local damage to the skin and its underlying tissues. It usually develops around bony prominences because of pressure or combination of pressure and friction (Amirifar et al. 2013). Pressure ulcer is a significant index of poor quality of patient care and one of the most crucial challenges encountered in the current health and medical treatment (Seong-Hi \& Lee 2016). Health care team staff spend a lot of time and energy managing the physical, emotional, and economic challenges of treating this disease (Mehrabani, Hosseini \& Karimloo 2012). About $10 \%$ of hospitalized patients and $5 \%$ of communityliving patients have varying degrees of PUs. In a review study of Karimian et al. On 5973 patients in Iran during 1998-2015, the incidence of PUs among hospitalized patients was reported as 19\% (Karimian et al. 2016).

About $95 \%$ of the pressure ulcers can be prevented (Fu Shaw et al. 2014), and nursing staff are responsible for direct care and ongoing prevention and treatment of pressure ulcers (Miyazaki, Caliri \& Santos 2010). Thus, in clinical care, the main emphasis is on awareness and understanding of the risk factors for PUs and appropri- ate preventive interventions (Coleman et al. 2013). Prevention of PUs is a priority in nursing care and a key indicator of nursing care quality (Soozani et al. 2012). General evaluation and in particular, risk assessment, is an essential part of nursing care (Dijkstra, Kazimier \& Halfens 2015). In the evidence-based guidelines for PU management, risk assessment is the most important issue (Balzer et al. 2014). Physical inactivity and lack of movement are considered the main cause of PU (Chaboyer et al. 2015).

The concept of daily living activities is often used to determine the level of self-care (Hilgenkamp, Van Wijck \& Evenhuis 2011). Daily living activities are defined as activities that a person normally performs on a daily basis to run an independent life (van het Bolscher-Niehuis et al. 2016). The Roper-Logan-Tierney Model for Nursing is a theory of nursing care introduced in 2000 based on Activities of Daily Living (ADL). It includes the biophysical activities needed to sustain life and activities that increase the quality of life. This model helps determine the measures needed for those who are physically or mentally dependent or unable to perform activities. In this regard, it helps nurses to plan and apply the care processes needed for patients to prevent secondary complications such as PUs (Aydın \& Mucuk 2015). 
Activities of daily living are divided to Basic Activity of Daily Living (BADL) such as bathing and grooming, and Instrumental Activity of Daily Living (IADL) such as shopping and money management (Seitz et al. 2014). Nurses as health care professionals have an important role in determining the care needs of patients, and they must be sure that the patients perform their ADLs at the highest possible level (Cerit 2014).

Natural changes due to aging, acute illness, exacerbation of chronic diseases, and hospitalization can reduce the ability of individuals to perform ADLs (Graf 2013). Caring plans involve continuous assessment by nurses to regain the performance and prevent further reduction through actions such as using physical or occupational therapies, if needed (Wallace \& Shelkey 2008).

Because of the multifactorial nature of the PU, effect of various factors on its incidence, and consistent with the Braden scale, researchers are highly interested in investigating all the factors associated with its creation and how they enhance the prediction of PU (Raju et al. 2015). In particular, those who are not active, have a poor sensory function and cannot perform their ADLs well are at higher risk of developing PU (Mostoufian 2015). Since the development of a PU is multifactorial and poorly understood, systematic monitoring of its incidence, risk assessment and preventive measures are essential (Raju et al. 2015). In addition, the extent of dependency to other family members may prepare the ground for development of PU.

The current study aims at investigating the relationship of BADL and IADL with the risk of developing PU among patients referred to teaching hospitals affiliated to Iran University of Medical Sciences (IUMS) in 2016. The results may help nurses and families make proper planning to increase the independency of these patients.

\section{Materials and Methods}

It is a descriptive, cross-sectional study. Research population consists of all patients referred to medical and surgical clinics affiliated to Iran University of Medical Sciences in 2017. The sample included patients aged above 45 years with rheumatoid, endocrine, cardiovascular, and pulmonology diseases referred to medical clinics and also patients with neurologic and orthopedic diseases referred to surgical clinics.

The sample was recruited using convenience cluster sampling method; the clusters were each teaching centers of Firouzgar and Rasool-e-Akram hospitals. Sam- pling from these hospitals was done in equal proportions. The sample size was calculated as 200 based on 95\% confidence level, $80 \%$ test power, and assuming that the correlation coefficient of BADL and IADL with the risk of developing PU should be at least 0.2 (to have a statistically significant relationship between them).

Data collection tool was a Persian-language questionnaire having four parts that was completed by the researcher. Part one surveys demographic characteristics, including gender, age, diagnosis, education level, weight, height, body mass index, presence or absence of pressure ulcer, degree and location of pressure ulcer if any, use or non-use of air mattresses, presence or absence of disability and underlying diseases, number and type of underlying diseases if any, and specific drug use. Part two includes Katz Index of BADL which assesses six subscales: Bathing, dressing, toileting, transferring, continence, and feeding. Each subscale is scored from 0-1.

A score of 6 indicates full independency, 3-5 moderate dependency, and 2 or less indicates severe dependency. Part 3 contains Lawton IADL Scale, which evaluates eight functions: Ability to use telephone, shopping, food preparation, housekeeping, laundry, mode of transportation, responsibility for own medications, and ability to manage finances. Patients are scored according to their highest level of functioning in that category. Score ranges from 0 (low function, dependent) to 8 (high function, independent) for women, and 0 through 5 for men. Finally, Part 4 includes Braden Scale for predicting pressure ulcer risk by examining six subclasses: Sensory perception, moisture, activity, mobility, and nutrition rated on a scale of 1 to 4 , and friction and shear subscale rated on a scale of 1 to 3 .

The total score ranges between 6 and 23. Higher score indicates a lower risk of developing pressure ulcer and vice versa. Based on this scale, pressure ulcer risks are divided into five groups: Very high risk (total score 9 or less), high risk (total score 10-12), moderate risk (total score 13-14), mild risk (total score 15-18), and no risk (total score 19-23).

To determine the reliability of the screening tools, after explaining the process to the caregivers or the patients, the first examiner completed the questionnaires through interview with the patients. After an interruption on the same day, the second examiner completed them again. The agreement between two examiners were tested by measuring the interclass correlation coefficient which were reported 0.959 for Katz Index, 0.963 for Lawton IADL scale, and 0.983 for Braden Scale. 
The collected data were analyzed in SPSS-PC V. 24. Descriptive analyses were done by calculating percentage, mean, standard deviation, and frequency distribution tables. With regard to inferential statistics, Kolmogorov-Smirnov test was used for testing the normality of data distribution. The results indicated that all three variables of BADL, IADL, and pressure ulcer risk were normally distributed.

The Independent T test, ANOVA, and Tukey's Test were used for examining the relationship between demographic characteristics and the mean pressure ulcer risk score. Next, the Pearson correlation test was done for examining the correlation of BADL and IADL scores with pressure ulcer risk score. Finally, the Spearman correlation test was employed for assessing the correlation between the BADL and IADL subscale scores with pressure ulcer risk score.

\section{Results}

Based on the results, more than half of participants were male $(55 \%)$. The mean age of the participants was 61.96 years. In terms of educational level, $54 \%$ of the participants had a high school diploma and $46 \%$ were illiterate. The mean weight of participants was $75.5 \mathrm{~kg}$, while their mean height and Body Mass Index (BMI) were $165.14 \mathrm{~cm}$ and $27.73 \mathrm{~kg} / \mathrm{m}^{2}$, respectively.

The most involved system was the neurological system $(28 \%)$. About half of the participants had underlying disease (45.5\%). Of the participants with underlying disease, $65.94 \%$ had one underlying disease. Among the underlying diseases, high blood pressure (24\%) and diabetes $(10.5 \%)$ had the highest incidence. Seven percent of participants had disabilities, and $35.5 \%$ were under specific medications, including nonsteroidal anti-inflammatory drugs, beta-blockers, blood diluents, inotropes, chemotherapeutic and radiotherapy drugs. Seven percent of the participants had pressure ulcers, and $78.5 \%$ of the pressure ulcers were grade 1 . None of the participants had grade 3, 4 or ungradable ulcers. Furthermore, $42.8 \%$ of the pressure ulcers were observed in sacral region and $35.7 \%$ in the buttocks. None of the patients used air mattresses (Table 1).

According to the findings, $66 \%$ of the subjects were independent in performing BADL, while $22 \%$ were moderately dependent and $12 \%$ dependent. The mean BADL score was reported 5.08. In performing IADLs, $17.5 \%$ were dependent, $41.5 \%$ moderately dependent and $41 \%$ were independent. The mean IADL score was 5.65 (Table 2).
According to the Braden scale, $2.5 \%$ were at high pressure ulcer risk, $3.5 \%$ at moderate risk, $10.5 \%$ at mild risk, and $83.5 \%$ at no risk. None of them was at very high pressure ulcer risk status (Table 2). The mean score of PU risk was 20.45. According to the results in Table 3 , higher dependence in performing BADLs $(r=0.720$, $\mathrm{P}<001)$ and IADLs $(\mathrm{r}=0.741, \mathrm{P}<001)$, increased the risk of developing pressure ulcers, also the effect of IADLs was higher than BADLs.

Age, underlying disease, disability and drug use had a significant positive relationship with the risk of developing pressure ulcers $(\mathrm{P}<0.001)$. The results of Tukey's post hoc test showed that patients over the age of 70 were at higher pressure ulcer risk compared to other age groups $(\mathrm{P}<0.01)$. There was a significant and negative relationship between educational level and the risk of developing pressure ulcer $(\mathrm{P}<0.001)$. Patients with a high school diploma or higher degree education were at lower risk of developing pressure ulcers $(\mathrm{P}<0.01)$ compared to lower levels of education. There was no statistically significant relationship between variables of "gender" and "BMI" with pressure ulcer risk $(\mathrm{P}<0.05)$. Since none of the participants had used air mattresses, the relationship between this variable and the pressure ulcer risk was not examined (Table 3 ).

Dependence in all subscales of BADL and IADL had a significant relationship with pressure ulcer risk $(\mathrm{P}<0.01)$, where dependence in transferring $(r=0.685)$ and toileting $(\mathrm{r}=0.626)$ as BADLs, and housekeeping $(\mathrm{r}=0.687)$ and mode of transportation $(\mathrm{r}=0.591)$ as IADLs showed higher correlation (Table 4).

\section{Discussion}

Many pressure ulcers are reasonably preventable through evidence-based care, but prevention requires knowledge of the associated factors with pressure ulcer development (Bergquist-Beringer \& Gajewski 2011). The results of the current study showed that most participants were independent in their BADL performance, but moderately dependent in performing their IADL.

In the study of Bourne (2009), most subjects were independent in performing BADL and IADL. Our results and Bourne' were the same in BADL part. The disagreement in terms of IADL results may be reasonable, because Bourne's study sample consisted of community people, but our study samples consisted of patients referred to the clinics. The findings of different studies are different in this regard (Karakurt et al. 2017). 
With respect to pressure ulcer risk and according to the findings, most participants were at no risk group of developing pressure ulcer, and none of them was at very high-risk group. In the studies of Akca et al. (2015) and Cremasco et al. (2013), most individuals were at very high risk group of developing pressure ulcer, which are contrary to our results. The difference may be because of difference in subjects. The subjects in Akca et al. Study were hospitalized patients who stayed a long time in a rehabilitation care center, and in Cremasco et al. Study, the samples were hospitalized in intensive care units.
The current study results indicate that dependence in BADL and IADL has a strong and direct relationship with the risk of developing pressure ulcer $(\mathrm{P}<0.01)$. Similarly, the results of Aydin and Mucuk in a rehabilitation center in Turkey also showed that individuals who were more dependent in BADLs and IADLs were at increased risk for the development of pressure ulcers $(\mathrm{P}<0.01)$ (Aydin \& Mucuk 2015). The results of Inan and Öztunç study entitled "Incidence of pressure ulcer in Turkey: A case study in an educational university" and findings of Kwong et al. Study entitled "Development

Table 1. Frequency distribution of demographic characteristics of study participants

\begin{tabular}{|c|c|c|c|}
\hline \multicolumn{2}{|c|}{ Demographic Characteristics } & \multirow{2}{*}{$\begin{array}{l}\text { No. } \\
110\end{array}$} & \multirow{2}{*}{$\begin{array}{l}\% \\
55\end{array}$} \\
\hline & Male & & \\
\hline Gerruet & Female & 90 & 45 \\
\hline \multirow{5}{*}{ Educational level } & Illiterate & 46 & 23 \\
\hline & Elementary school & 40 & 20 \\
\hline & Junior high school & 30 & 15 \\
\hline & Senior high school & 54 & 27 \\
\hline & Bachelor or higher & 30 & 15 \\
\hline \multirow{4}{*}{ Age (y) } & 50 and less & 48 & 24 \\
\hline & $51-60$ & 52 & 26 \\
\hline & $61-70$ & 50 & 25 \\
\hline & $>70$ & 50 & 25 \\
\hline \multirow{5}{*}{ Weight (kg) } & 60 and less & 31 & 15.5 \\
\hline & $61-70$ & 51 & 25.5 \\
\hline & $70-80$ & 50 & 25 \\
\hline & $81-90$ & 39 & 19.5 \\
\hline & $>90$ & 29 & 14.5 \\
\hline \multirow{4}{*}{ Height $(\mathrm{cm})$} & 160 and less & 72 & 36 \\
\hline & $161-170$ & 83 & 41.5 \\
\hline & $171-180$ & 39 & 19.5 \\
\hline & $>180$ & 6 & 3 \\
\hline \multirow{6}{*}{ Involved system } & Musculoskeletal system & 30 & 15 \\
\hline & Cardiovascular system & 30 & 15 \\
\hline & Lung & 28 & 14 \\
\hline & Neurological system & 56 & 28 \\
\hline & Joint system & 28 & 14 \\
\hline & Endocrine system & 28 & 14 \\
\hline
\end{tabular}




\begin{tabular}{|c|c|c|c|}
\hline \multicolumn{2}{|c|}{ Demographic Characteristics } & \multirow{2}{*}{$\begin{array}{c}\text { No. } \\
14\end{array}$} & \multirow{2}{*}{$\begin{array}{l}\% \\
7\end{array}$} \\
\hline & Yes & & \\
\hline Disavimty & No & 186 & 93 \\
\hline \multirow{2}{*}{ Underlying disease } & Yes & 91 & 45.5 \\
\hline & No & 109 & 54.5 \\
\hline \multirow{4}{*}{ Number of underlying dis } & 0 & 109 & 54.5 \\
\hline & 1 & 60 & 30 \\
\hline & 2 & 28 & 14 \\
\hline & 3 & 3 & 1.5 \\
\hline \multirow{6}{*}{$\mathrm{BMI}\left(\mathrm{kg} / \mathrm{m}^{2}\right)$} & $<18.5$ & 5 & 2.5 \\
\hline & $18.5-24.9$ & 52 & 26 \\
\hline & $25.9-29$ & 83 & 41.5 \\
\hline & $30.9-34$ & 46 & 23 \\
\hline & $35.9-39$ & 7 & 3.5 \\
\hline & $>40$ & 7 & 3.5 \\
\hline \multirow{16}{*}{ Type of underlying disea } & High blood pressure & 48 & 24 \\
\hline & Rheumatism & 4 & 2 \\
\hline & Arthritis & 2 & 1 \\
\hline & High blood fat & 9 & 4.5 \\
\hline & Kidney Disease & 5 & 2.5 \\
\hline & Cardiovascular disease & 9 & 4.5 \\
\hline & Heart valve disease & 4 & 2 \\
\hline & Cancer & 2 & 1 \\
\hline & Diabetes & 21 & 10.5 \\
\hline & Hyperthyroidism & 2 & 1 \\
\hline & Osteoporosis & 8 & 4 \\
\hline & Cerebrovascular disease & 2 & 1 \\
\hline & Lung failure & 1 & 0.5 \\
\hline & Asthma & 3 & 1.5 \\
\hline & Heart failure & 1 & 0.5 \\
\hline & Hypothyroidism & 4 & 2 \\
\hline \multirow{2}{*}{ Specific drug use } & Yes & 71 & 35.5 \\
\hline & No & 129 & 64.5 \\
\hline \multirow{2}{*}{ Presence of PU } & Yes & 14 & 7 \\
\hline & No & 186 & 93 \\
\hline
\end{tabular}




\begin{tabular}{|c|c|c|c|}
\hline & & No. & $\%$ \\
\hline \multirow{2}{*}{ PU grade } & 1 & 11 & 78.5 \\
\hline & 2 & 3 & 21.5 \\
\hline \multirow{4}{*}{ PU location } & Buttocks & 5 & 35.7 \\
\hline & Sacrum & 6 & 42.85 \\
\hline & Heel & 2 & 14.28 \\
\hline & Shoulder & 1 & 7.14 \\
\hline
\end{tabular}

of pressure ulcers in the elderly in nursing and home care centers: the impact of factors" similar to our study indicate that there is a significant relationship between pressure ulcer and independence level (Inan \& Öztunç 2012; Kwong et al. 2009).

Bergquist-Beringer and Gajewski study findings showed a direct correlation between the level of dependence in BADL and IADL and pressure ulcer risk (BergquistBeringer \& Gajewski, 2011). The results of this study is similar to the results of Dijkstra et al. Study entitled "Using the care dependency scale for identifying patients at risk for pressure ulcer". They found out that dependency level can distinguish between patients at risk for pressure ulcer development and those who are not at risk (Dijkstra, Kazimier \& Halfens 2015).

In this study, there were significant correlations between the risk of pressure ulcer development and variables of age, underlying diseases, disability, and specific drug use $(\mathrm{P}<0.001)$. The results of review and metaanalysis study of Karimian et al. Entitled "The incidence of pressure ulcer in Iran: A systematic review study and meta-analysis" in 2014 indicate that the prevalence of pressure ulcer increases with the increase of age (Karimian et al. 2016).

Raju et al. (2015) In their study entitled "Investigating factors associated with pressure ulcer development: An analytical method" found out that age had a statistically significant and positive correlation with pressure ulcer development $(\mathrm{P}<0.001)$. In the review study of Sedghi Goyaghaj et al. (2016) entitled "the underlying factors of pressure ulcer and its treatment and prevention", the patient's age along with several other factors was identified as the most important predictors of pressure ulcers.

These study findings are in agreement with our study that could be due to lower movement in the elderly people. Akbari Sari et al. (2011) Concluded that age and

Table 2. Frequency distribution of participants with respect to BADL, IADL, and PU risk

\begin{tabular}{|c|c|c|c|}
\hline & & No. & $\%$ \\
\hline \multirow{3}{*}{ BADL } & Independent & 132 & 66 \\
\hline & Moderate dependent & 44 & 22 \\
\hline & Dependent & 24 & 12 \\
\hline \multirow{3}{*}{$\mathrm{IADL}$} & Independent & 82 & 41 \\
\hline & Moderate dependent & 83 & 41.5 \\
\hline & Dependent & 35 & 17.5 \\
\hline \multirow{5}{*}{ PU risk } & High risk & 5 & 2.5 \\
\hline & Moderate risk & 7 & 3.5 \\
\hline & & & \\
\hline & Mild risk & 21 & 10.5 \\
\hline & No risk & 167 & 83.5 \\
\hline
\end{tabular}


Table 3. Relationship of BADL, IADL, and demographic factors with the mean PU risk score

\begin{tabular}{|c|c|c|c|}
\hline & Variable & Mean PU Risk & Test Results \\
\hline $\begin{array}{c}\text { BADL } \\
\text { ANOVA test results }\end{array}$ & $\begin{array}{c}\text { Independent }(n=132) \\
\text { Moderate dependent }(n=44) \\
\text { Dependent }(n=24)\end{array}$ & $\begin{array}{l}21.53 \\
19.84 \\
15.62\end{array}$ & $\begin{aligned} & F=45.95 \\
& d_{1}=2, f_{2}=197 \\
& P<0.001\end{aligned}$ \\
\hline $\begin{array}{c}\text { IADL } \\
\text { ANOVA test results }\end{array}$ & $\begin{array}{c}\text { Independent }(n=82) \\
\text { Moderate dependent }(n=83) \\
\text { Dependent }(n=35)\end{array}$ & $\begin{array}{l}21.73 \\
21.11 \\
15.89\end{array}$ & $\begin{array}{c}F=150.31 \\
d_{1}=2, d_{2}=197 \\
P<0.001\end{array}$ \\
\hline $\begin{array}{l}\text { Gender } \\
\text { Independent t-test } \\
\text { results }\end{array}$ & $\begin{array}{l}\text { Female }(n=90) \\
\text { Male }(n=110)\end{array}$ & $\begin{array}{l}20.75 \\
20.08\end{array}$ & $\begin{array}{c}T=0.711 \\
d f=198 \\
P=0.089\end{array}$ \\
\hline $\begin{array}{l}\text { Educational level } \\
\text { ANOVA test results }\end{array}$ & $\begin{array}{l}\text { Illiterate }(n=46) \\
\text { Elementary school }(n=40) \\
\text { Junior high school }(n=30) \\
\text { Senior high school }(n=54) \\
\text { Bachelor or higher }(n=30)\end{array}$ & $\begin{array}{l}19.28 \\
19.08 \\
21.10 \\
21.17 \\
22.13\end{array}$ & $\begin{aligned} & F=10.50 \\
&{d f_{1}}_{1}=2, d_{2}=195 \\
& P<0.001\end{aligned}$ \\
\hline $\begin{array}{c}\text { Age, } y \\
\text { ANOVA test results }\end{array}$ & $\begin{array}{l}50 \text { and less }(n=48) \\
51-60(n=52) \\
61-70(n=50) \\
>70(n=50)\end{array}$ & $\begin{array}{l}21.60 \\
21.08 \\
20.60 \\
18.54\end{array}$ & $\begin{aligned} F & =14.33 \\
d_{1}=2, & d f_{2}=195 \\
P & <0.001\end{aligned}$ \\
\hline $\begin{array}{l}\mathrm{BMI}, \mathrm{kg} / \mathrm{m}^{2} \\
\text { ANOVA test results }\end{array}$ & $\begin{array}{c}<25(n=57) \\
25-25.9(n=83) \\
>30(n=63)\end{array}$ & $\begin{array}{l}20.30 \\
20.52 \\
20.52\end{array}$ & $\begin{array}{c}F=0.140 \\
{d f_{1}}_{1}=2, d_{2}=197 \\
P=0.870\end{array}$ \\
\hline $\begin{array}{l}\text { Underlying disease } \\
\text { Independent t-test } \\
\text { results }\end{array}$ & $\begin{array}{l}\text { Yes }(n=91) \\
\text { No }(n=109)\end{array}$ & $\begin{array}{l}19.58 \\
21.17\end{array}$ & $\begin{array}{l}T=4.103 \\
d f=198 \\
P<0.001\end{array}$ \\
\hline $\begin{array}{l}\text { Disability } \\
\text { Independent t-test } \\
\text { results }\end{array}$ & $\begin{array}{l}\text { Yes }(n=14) \\
\text { No }(n=186)\end{array}$ & $\begin{array}{l}18.14 \\
20.62\end{array}$ & $\begin{array}{l}T=3.355 \\
d f=198 \\
P<0.01\end{array}$ \\
\hline $\begin{array}{l}\text { Specific drug use } \\
\text { Independent t-test } \\
\text { results }\end{array}$ & $\begin{array}{l}\text { Yes }(n=71) \\
\text { No }(n=129)\end{array}$ & $\begin{array}{l}3.11 \\
44.2\end{array}$ & $\begin{array}{l}T=2.45 \\
d f=198 \\
P<0.05\end{array}$ \\
\hline
\end{tabular}

some of underlying diseases like diabetes and high blood pressure had a correlation with the pressure ulcer risk, which is consistent with our results. Keller et al. (2002) Also proved the effect of impaired blood circulation and diabetes on pressure ulcer development. Underlying diseases with their associated problems such as inactivity or decreased tissue hypoperfusion can increase the risk of pressure ulcer. Disability can also increase the risk of pressure ulcer development by restricting mobility and taking medications such as non-steroidal anti-inflammatory drugs and beta-blockers altering the metabolism of the body. 
Table 4. Results of the relationship between BADL and IADL subscales with the PU risk scores

\begin{tabular}{|c|c|c|c|}
\hline \multirow{2}{*}{\multicolumn{2}{|c|}{ Variable }} & \multicolumn{2}{|c|}{ PU Risk } \\
\hline & & $\mathbf{R}$ & Sig. \\
\hline \multirow{6}{*}{ Subscales of BADL } & Bathing & 0.581 & $<0.0001$ \\
\hline & Dressing & 0.584 & $<0.0001$ \\
\hline & Toileting & 0.626 & $<0.0001$ \\
\hline & Transferring & 0.685 & $<0.0001$ \\
\hline & Continence & 0.292 & $<0.0001$ \\
\hline & Feeding & 0.352 & $<0.0001$ \\
\hline \multirow{8}{*}{ Subscales of IADL } & Ability to use telephone & 0.370 & $<0.0001$ \\
\hline & Shopping & 0.409 & $<0.0001$ \\
\hline & Food preparation & 0.408 & $<0.0001$ \\
\hline & Housekeeping & 0.687 & $<0.0001$ \\
\hline & Laundry & 0.538 & $<0.0001$ \\
\hline & Using transportation vehicles & 0.591 & $<0.0001$ \\
\hline & Responsibility for own medications & 0.552 & $<0.0001$ \\
\hline & Ability to manage finances & 0.409 & $<0.0001$ \\
\hline
\end{tabular}

In this study, a negative correlation was found between the level of education and the risk of developing pressure ulcer $(\mathrm{P}<0.001)$. It seems that increasing knowledge and awareness of people can have a positive effect on their performance in preventing diseases and complications such as pressure ulcers.

In this study, gender and BMI factors had no statistically significant relationship with the pressure ulcer development risk $(\mathrm{P}>0.05)$. This is consistent with the findings of Raju et al. (2015) $(\mathrm{P}<0.05)$ and Keller et al. (2002) who also found no relationship between gender and pressure ulcer risk. Based on the results of some studies, individuals with BMI of less than 18.5 are at higher risk of developing pressure ulcers $(\mathrm{P}<0.001)$ (Akca, Aydin \& Gümüs 2015). This finding disagrees with our finding. The different results might be due to different study samples. Aydın and Mucuk (2015) found that people with a lower BMI had a higher risk of developing pressure ulcer. This study was conducted in a rehabilitation center that its different results with ours were due to different samples.

The findings of this research can be useful in education, service delivery, and management areas. In the field of education, it is necessary to hold training classes and methods for nursing staff in order to teach them patients' empowerment techniques. Also training programs for patients, public community, especially older people should be held with respect to strategies for increasing independence, performing ADLs, and decreasing dependence to care givers. In the area of service delivery, nursing staff can play different roles in the daily living of people; for example, they can provide individuals with step-by-step instructions for performing activities. In addition, nurses can substitute activities that do not encourage independency and physical activity with proper activities, or in order to reduce dependency, recommend using mechanical appliances such as crutches, canes, or walkers for the elderly.

In the field of management, the most important aspect of optimizing management plans is the active and desirable presence of patients in care management. Nursing managers, by using individual-based care models, can increase the participation of patients in daily living activities and reduce their dependence in these activities. In this regard, they improve the self-care of individuals and help them prevent complications such as PUs by creating a stimulating environment. It should be noted that 
due to the descriptive and cross-sectional nature of the study and the self-reporting assessment tools, the results of the study should be used with caution.

\section{Ethical Considerations}

Compliance with ethical guidelines

After obtaining approval from the Regional Ethics Committee of Iran University of Medical Sciences (Code: IR.IUMS.FMD.REC) and written and verbal consent from the subjects, the questionnaires were completed by observation and interview.

Funding

The Nursing Research Center of Iran University of Medical Sciences (Code No. 32352) approved and funded this study.

\section{Authors contributions}

Authors contribution is as follows: Conceptualization: Forough Rafii, Sahar Mohammadi, and Tahmine Salehi; Methodology: Forough Rafii, Sahar and Mohammadi; Investigation: Sahar Mohammadi; Writing original draft: Sahar Mohammadi; Formal analysis; Sahar Mohammadi and Hamid Haghani; Review and editing; Forough Rafii; Supervision and project administration: Forough Rafii; and Funding acquisition: Forough Rafii.

\section{Conflict of interest}

The authors declared no conflict of interest.

\section{References}

Akbari Sari, A., et al., 2011. [Factors affecting pressure ulcer in the ICU units of Tehran University of Medical Sciences teaching hospitals (Persian)]. Journal of School of Public Health and Institute of Public Health Research, 8(3), pp. 81-92.

Akca, N. K., Aydin, G. \& Gümüs, K., 2015. Pressure ulcers and their associated factors in nursing home inmates. Journal of College of Physicians and Surgeons Pakistan, 25(1), pp. 27-30. [PMID]

Amirifar, S., et al., 2013. Predictive value of Braden scale in pressure ulcer occurrence in hospitalized patients. Journal of Holistic Nursing and Midwifery, 23(2), pp. 8-15.

Aydın, G. \& Mucuk, S., 2015. The evaluation of daily living activities, pressure sores and risk factors. Rehabilitation Nursing 40(2), pp. 84-91. [DOI:10.1002/rnj.145] [PMID]

Balzer, K., et al., 2014. What patient characteristics guide nurses' clinical judgement on pressure ulcer risk? A mixed methods study. International Journal of Nursing Studies, 51(5), pp. 703-16. [DOI:10.1016/j.ijnurstu.2013.09.005] [PMID]

Bergquist Beringer, S. \& Gajewski, B. J., 2011. Outcome and assessment information set data that predict pressure ulcer development in older adult home health patients. Advances in Skin \& Wound Care, 24(9), pp. 404-14. [DOI:10.1097/01. ASW.0000405215.49921.a9] [PMID]

Bourne, P. A., 2009. Activities of daily living, instrumental activities for daily living and predictors of functional capacity of older men in Jamaica. North American Journal of Medical Sciences, 1(4), pp. 184-92. [PMID] [PMCID]

Cerit, B., 2014. Determinationand evaluation of the needs of the patients with knee osteoarthritis in their daily living activities. Procedia-Social and Behavioral Sciences, 152(2014), pp. 841-4. [DOI:10.1016/j.sbspro.2014.09.331]

Chaboyer, W., et al., 2015. Physical activity levels and torso orientations of hospitalized patients at risk of developing a pressure injury: An observational study. International Journal of Nursing Practice, 21(1), pp. 11-7. [DOI:10.1111/ijn.12188] [PMID]

Coleman, S., et al., 2013. Patient risk factors for pressure ulcer development: Systematic review. International Journal of Nursing Studies, 50(7), pp. 974-1003. [DOI:10.1016/j.ijnurss tu.2012.11.019] [PMID]

Cremasco, M. F., et al., 2013. Pressure ulcers in the intensive care unit: The relationship between nursing workload, illness severity and pressure ulcer risk. Journal of Clinical Nursing, 22(15), pp. 2183-91. [DOI:10.1111/j.1365-2702.2012.04216.x] [PMID]

Dijkstra, A., Kazimier, H. \& Halfens, R. J., 2015. Using the care dependency scale for identifying patients at risk for pressure ulcer. Journal of Advanced Nursing, 71(11), pp. 2529-39. [DOI:10.1111/jan.12713] [PMID]

Fu Shaw, L., et al., 2014. Incidence and predicted risk factors of pressure ulcers in surgical patients: Experience at a medical center in Taipei, Taiwan. BioMed Research International, 2014, 416896.[DOI:10.1155/2014/416896]

Gorecki, C., et al., 2009. Impact of pressure ulcers on quality of life in older patients: A systematic review. Journal of the American Geriatrics Society, 57(7), pp. 1175-83. [DOI:10.1111/j.15325415.2009.02307.x] [PMID]

Graf, C., 2013. The Lawton Instrumental Activities of Daily Living (IADL) scale. American Journal of Nursing, 108(4), pp. 52-62.

Hilgenkamp, T. I., Van Wijck, R. \& Evenhuis, H. M., 2011. (Instrumental) activities of daily living in older adults with intellectual disabilities. Research in Developmental Disabilities, 32(5), pp. 1977-87. [DOI:10.1016/j.ridd.2011.04.003] [PMID]

Inan, D. G. \& Öztunç, G., 2012. Pressure ulcer prevalence in Turkey: A sample from a university hospital. Journal of Wound Ostomy \& Continence Nursing, 39(4), pp. 409-13. [DOI:10.1097/ WON.0b013e31825825b1] [PMID]

Karakurt, P., et al., 2017. The effect of activities of daily living on the self-care agency of patients in a cardiovascular surgery clinic. Journal of Vascular Nursing, 35(2), pp. 78-85. [DOI:10.1016/j.jvn.2016.10.004] [PMID]

Karimian M., et al., 2016. Prevalence of bedsore in Iran: A systematic review and meta-analysis. Journal of Mazandaran University of Medical Sciences, 26(136), pp. 202-10. 
Keller, P. B., et al., 2002. Pressure ulcers in intensive care patients: a review of risks and prevention. Intensive Care Medicine, 28(10), pp. 1379-88.

Kwong, E. W. Y., et al., 2009. Pressure ulcer development in older residents in nursing homes: Influencing factors. Journal of Advanced Nursing, 65(12), pp. 2608-20. [DOI:10.1111/j.13652648.2009.05117.x] [PMID]

Mehrabani, M., Hosseini, M. A. \& Karimloo, M., 2012. Comparison of honey dressing with Hydrocolloid dressing effects on pressure ulcer healing of ICU hospitalized patients. Journal of Health Promotion Management, 1(3), pp. 37-45.

Miyazaki, M. Y., Caliri, M. H. L. \& Santos, C. B. D., 2010. Knowledge on pressure ulcer prevention among nursing professionals. Revista Latino-Americana de Enfermagem, 18(6), pp. 1203-11. [DOI:10.1590/S0104-11692010000600022] [PMID]

Mostoufian, F., 2015. Prevention pressure ulcer guideline, [Internet]. Viewed 2 January 2017, https://treatment.sbmu.ac.ir/ uploads/008-Pressure_Ulcer_Prevention_Guideline.pdf

Raju, D., et al., 2015. Exploring factors associated with pressure ulcers: a data mining approach. International journal of Nursing Studies, 52(1), pp. 102-11. [DOI:10.1016/j.ijnurstu.2014.08.002] [PMID]

Sedghi Goyaghaj, N., et al., 2016. [The causes and prevention and treatment of pressure ulcers (Persian)]. Journal of AJA Faculty of Nursing, 15(2), pp. 37-47.

Seitz, D. P., et al., 2014. Effects of impairment in activities of daily living on predicting mortality following hip fracture surgery in studies using administrative healthcare databases, BMC Geriatrics, 14(1), p. 9. [DOI:10.1186/1471-2318-14-9] [PMID] [PMCID]

Seong Hi, P. \& Lee, H. S., 2016. Assessing predictive validity of pressure ulcer risk scales-A systematic review and meta-analysis. Iranian Journal of Public Health, 45(2), pp. 122-33.

Soozani, A., et al., 2012. [The effect of education on knowledge and performance of nurses in prevention and control of pressure sore (Persian)]. Modern Care, Scientific Quarterly of Birjand Nursing and Midwifery Faculty, 9(1), pp. 16-23.

van het Bolscher Niehuis, M. J., et al., 2016. Effects of self-management support programmes on activities of daily living of older adults: A systematic review. International Journal of Nursing Studies, 61, pp. 230-47. [DOI:10.1016/j.ijnurstu.2016.06.014] [PMID]

Wallace, M. \& Shelkey, M., 2008. Monitoring functional status in hospitalized older adults. The American Journal of Nursing, 108(4), pp. 64-71. [DOI:10.1097/01.NAJ.0000314811.46029.3d] [PMID] 